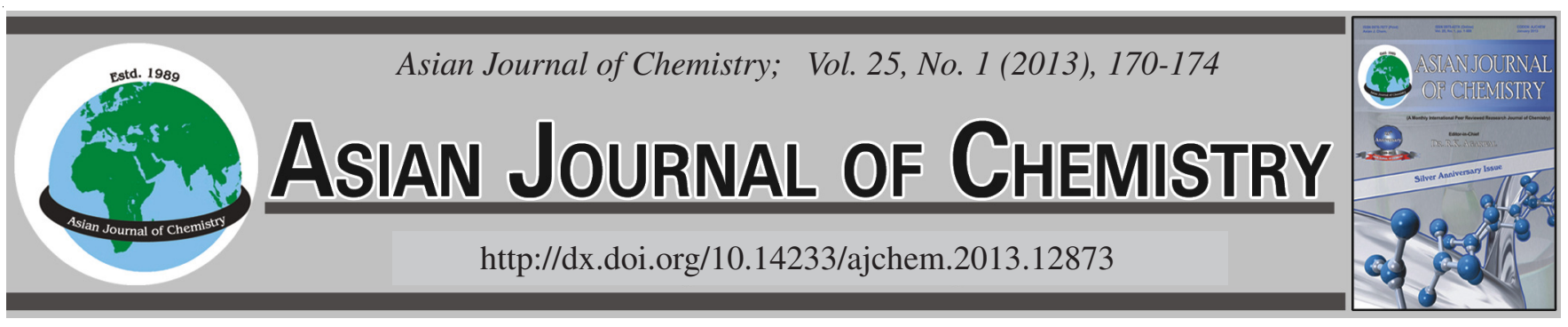

\title{
Cis and Trans Isomers of 1-Hydroxyiminoalkylferrocenes and Their Antioxidant Activity
}

XiQING Sun, JiAn Zhang* and LongFei Jin

College of Chemistry and Materials, South-Central University for Nationalities, Wuhan 430074, P.R. China

*Corresponding author: E-mail: jianzhangye@gmail.com

\begin{abstract}
Condensation reactions of acylferrocene with hydroxylamine hydrochloride afforded a series of acylferrocene oximes, 1-hydroxyiminoalkylferrocenes (3a-d) and each separated into cis and trans isomers which has antioxidant activity towards DPPH'. Kinetics parameters $(\log \mathrm{Z})$ for the reaction of samples with $\mathrm{DPPH}^{\bullet}$ were determined. The result indicates that 1-hydroxyiminoalkylferrocenes have antioxidant properties which are related to the stereochemistry of the $\alpha$-substituent hydroxyimino group. Because of a long conjugated chain, resulting in electron delocalization, the antioxidant activity of (3a-d) is better than BHT and enhanced with the increase of compounds concentration of (3a-d), but reduced as the bulkiness of the $\alpha$-substituent hydroximino group increased. The antioxidant activity of 1-hydroxyiminoalkylferrocene was much higher than that of the precursors (acylferrocenes). Antioxidant activity of cis-isomers is slightly bigger than that of trans-isomers.
\end{abstract}

Key Words: Hydroxyiminoalkylferrocene, Antioxidant activity, Acylferrocene, DPPH, Synthesis, Cis and trans isomers.

\section{INTRODUCTION}

The chemistry of ferrocene and its derivatives attracted a considerable interest in the last decade ${ }^{1-10}$ because ferrocenyl compounds have many applications in the synthesis of mononuclear and binuclear complexes ${ }^{11-15}$ and electrochemistry ${ }^{16-18}$ potential uses as biosensors ${ }^{19,20}$ and catalysis ${ }^{21-24}$. But, to the best of our knowledge, there is scanty information about the antioxidant activity of ferrocenyl compounds. Recently, antioxidant activity of the acylferrocene oxime compounds, bis-hydroxyiminoalkylferrocenes was investigated with $\mathrm{DPPH}^{\circ}$, the related works have been reported ${ }^{25}$, acylferrocene oxime as a new substitute possessing scavenging DPPH confers interesting antioxidant properties. In this present work, several mono-hydroxyiminoalkylferrocenes were synthesized from acylferrocene and their antioxidant properties were evaluated.

$\mathrm{EC}_{50}$ values are often used as an indicator to determine the ability of the sample scavenging DPPH, but, due to the complexity and diversity reactions of sample with DPPH, this result in complex products, varying reaction rates and altered stoichiometry, all of which may affect the reliability of $\mathrm{EC}_{50}$ values $^{26}$. As an improved alternative evaluation, $\log \mathrm{Z}$ appears as a better descriptor of phenol reactivity toward $\mathrm{DPPH}^{\bullet}$ than $\mathrm{EC}_{50}{ }^{26,27}$, we obtained the well result trying this parameter $\log \mathrm{Z}$ to quantify antioxidant activity of acylferrocene oxime.

\section{EXPERIMENTAL}

All chemicals and solvents were obtained from Sinopharm Chemical Reagent Co. Ltd. (Shanghai, People's Republic of China). Acylferrocenes were prepared from ferrocene. The yields referred to analytically pure compounds and were not optimized. Melting points were taken on a capillary meltingpoint apparatus and were uncorrected. ${ }^{1} \mathrm{H}$ and ${ }^{13} \mathrm{C}$ NMR spectra were recorded, respectively with a Varian Mercury 300 and an Avance Bruker 600 spectrometer using TMS as an internal standard in $\mathrm{CDCl}_{3}$ as a solvent. IR spectra were recorded on a NEXUS-470 IR spectrometer, using KBr pellets. Elemental analyses were performed in a FLASH-1112 instrument. Electronic absorptions were recorded on a PERKIN ELMER UV/ VIS LAMBOA-35 automatic spectrophotometer in $\mathrm{CHCl}_{3}$.

Formylferrocene (2a): Ferrocene (1.86 g, $0.01 \mathrm{~mol}$ ) was added over a period of $0.5 \mathrm{~h}$ to a vigorously stirred solution prepared from $3.60 \mathrm{~g}(0.027 \mathrm{~mol})$ of $\mathrm{N}$-methyl-formanilide and $3.06 \mathrm{~g}$ ( $0.02 \mathrm{~mol})$ of phosphorus oxychloride. The mixture was stirred for $3 \mathrm{~h}$ at $60{ }^{\circ} \mathrm{C}$ in a nitrogen atmosphere. The mixture was then cooled to $0{ }^{\circ} \mathrm{C}$ and $10 \mathrm{~g}$ of sodium acetate dissolved in $80 \mathrm{~mL}$ of water was added and the solution stirred overnight. The reaction mixture was extracted twice with 70 $\mathrm{mL}$ ether and extracts were washed successively with $1 \mathrm{~N} \mathrm{HCl}$, water and saturated sodium bicarbonate solution and finally water, the solvent was removed and the crude products were purified by recrystallization from cyclohexane-chloroform. 
The yield was $80 \%$, m.p. $122-124{ }^{\circ} \mathrm{C}$. (reported ${ }^{28}$ m.p. 121$123^{\circ} \mathrm{C}$ ). Calcd. (\%) for $\mathrm{C}_{11} \mathrm{H}_{10} \mathrm{OFe}: \mathrm{C}, 61.69 ; \mathrm{H}, 4.67$. Found $(\%)$ : C, 62.28; H, 4.59 .

Acetylferrocene (2b): Ferrocene (1.86 g, $0.01 \mathrm{~mol})$, dissolved in $30 \mathrm{~mL}$ of dry chloroform, was added over a period of $0.5 \mathrm{~h}$ to a stirred mixture of aluminum chloride $(6.72 \mathrm{~g}$, $0.05 \mathrm{~mol})$ and acetic anhydride $(5 \mathrm{~mL}, 0.05 \mathrm{~mol})$ in $100 \mathrm{~mL}$ of dry chloroform at $4-6^{\circ} \mathrm{C}$. After which, the reaction was carried out at $40^{\circ} \mathrm{C}$ with immediate evolution of hydrogen chloride and formation of an intensely violet solution. The mixture was stirred at $40{ }^{\circ} \mathrm{C}$ for $1 \mathrm{~h}$ and then cooled and decomposed with ice. Organic layers were washed with water, $5 \%$ sodium bicarbonate solution and water. The separated aqueous phase was extracted several times with chloroform and combined with the main body of organic solution. The deep red organic solution was dried under vacuum and the crude product was purified by recrystallization from $50 \mathrm{~mL}$ cyclohexanechloroform (1:1) solvent and large red-brown rectangular plates of acetylferrocene deposited. The second crop after one recrystallization weighed 2.10 g $(92 \%)$, m.p. $84-85^{\circ} \mathrm{C}$; reported ${ }^{29}$ m.p. $85-86^{\circ} \mathrm{C}$. Calcd. (\%) for $\mathrm{C}_{12} \mathrm{H}_{12} \mathrm{OFe}$ : C, 63.16; H, 5.26. Found (\%): C, 62.28; H, 5.10.

Compounds $\mathbf{2 c - d}$ was prepared using the same procedure as $\mathbf{2 b}$. After the usual workup, the crude products were purified by recrystallization from cyclohexane-chloroform, ratio: (1:1 for $\mathbf{2} \mathbf{a} ; 2: 1$ for $\mathbf{2 c - d}$ ) to afford propionylferrocene (2c), yield $87 \%$, red oily liquid. Calcd. (\%) for $\mathrm{C}_{13} \mathrm{H}_{14} \mathrm{OFe}: \mathrm{C}, 64.46 ; \mathrm{H}$, 5.78; Found (\%): C, 65.67; H, 5.75.

Butyrylpropionyl ferrocene (2d): Yield $84 \%$, red m.p. 36-38 ${ }^{\circ} \mathrm{C}$. Calcd. (\%) for $\mathrm{C}_{14} \mathrm{H}_{16} \mathrm{OFe}: \mathrm{C}, 76.56$; H, 6.25; Found (\%): C, 75.98; H, 6.55 .

Hydroxyiminoalkylferrocene (3a-d): $2.10 \mathrm{~g}$ (0.03 mol) hydroxylamine hydrochloride dissolved in $5 \mathrm{~mL}$ of water was added to a flask containing $0.02 \mathrm{~mol}$ of carbonyl components 2a-d in $100 \mathrm{~mL}$ anhydrous ethanol and stirred at room temperature for a while to the full mixing and $3.2 \mathrm{~g}$ of $\mathrm{NaOH}$ was added. The mixture was stirred at reflux temperature. Reaction times: $0.5 \mathrm{~h}$ (for $\mathbf{2} \mathbf{a}$ to give $\mathbf{3} \mathbf{a}$, for $\mathbf{2 b}$ to give $\mathbf{3 b}$ ); $1 \mathrm{~h}$ (for $\mathbf{2} \mathbf{c}$ to give $\mathbf{3 c}$ ); $1.2 \mathrm{~h}$ (for $\mathbf{2 d}$ to give $\mathbf{3 d}$ ). The solvent was removed under reduced pressure. The mixture was added into $50 \mathrm{~mL}$ $8 \%$ ice-cold diluted hydrochloric acid, the products separated as orange $(\mathbf{3 a}, \mathbf{3 b})$; red $(\mathbf{3 c}, \mathbf{3 d})$ precipitates were filtered off and washed with ice water and dried under vacuum. The residue was chromatographed on alumina with ethyl acetate as eluent and separated into two portions (the first eluted portion and the residual portion), respectively corresponding to transisomer and cis-isomer. Both were repeatedly recrystallizcd from hexane.

(E)-Hydroxyiminomethylferrocene (3aE): Orange yellow needle. Yield $(\mathrm{E}+\mathrm{Z}): 84 \%$. m.p. $115-117^{\circ} \mathrm{C} . \mathrm{C}_{11} \mathrm{H}_{11} \mathrm{FeNO}$. Calcd. (\%) C 57.64, H 4.80, N 6.11; found (\%). C 58.00, H 4.88, N 6.19. IR (KBr, $\left.v_{\max }, \mathrm{cm}^{-1}\right): 3317(\mathrm{OH}) ; 1319(\delta \mathrm{OH})$; $1638(\mathrm{C}=\mathrm{N}) ; 959(\mathrm{~N}-\mathrm{O}) .{ }^{1} \mathrm{H}$ NMR $\left(\mathrm{CDCl}_{3}\right) \delta: 8.00(\mathrm{~s}, \mathrm{H}, \mathrm{H}-$ $\mathrm{C}=\mathrm{N}), 4.13$ (s, 5H, C $\left.\mathrm{p}_{\text {unsubst }}\right) ; 4.49\left(\mathrm{~m}, 2 \mathrm{H}, \beta \mathrm{H}-\mathrm{Cp}_{\text {subst }}\right), 4.64(\mathrm{~m}$, $\left.2 \mathrm{H}, \alpha \mathrm{H}-\mathrm{Cp}_{\text {subst }}\right) ; 6.80$ (br-s, H, -OH). ${ }^{13} \mathrm{C} \mathrm{NMR}\left(\mathrm{CDCl}_{3}\right) \delta$ : 66.74-69.82 [Fc,C(2-10)]; 84.14 [Fc,C(1)]; $150.72(\mathrm{C}=\mathrm{N})$.

(Z)-Hydroxyiminomethylferrocene $(3 a Z)$ : Orange yellow flake. m.p. $151-153{ }^{\circ} \mathrm{C} . \mathrm{C}_{11} \mathrm{H}_{11} \mathrm{FeNO}$. Calcd. (\%) $\mathrm{C}$ 57.64, H 4.80, N 6.11; found (\%) C 58.04, H 4.83, N 6.12. IR
$\left(\mathrm{KBr}, \mathrm{v}_{\max }, \mathrm{cm}^{-1}\right): 3312(\mathrm{OH}) ; 1313(\delta \mathrm{OH}) ; 1648(\mathrm{C}=\mathrm{N}) ; 956$ $(\mathrm{N}-\mathrm{O}) .{ }^{1} \mathrm{H}$ NMR $\left(\mathrm{CDCl}_{3}\right) \delta: 7.59$ (s, H, H-C=N), 4.12(s, 5H, $\left.\mathrm{Cp}_{\text {unsubst }}\right) ; 4.50$ (m, 2H, $\left.\beta \mathrm{H}-\mathrm{Cp}_{\text {subst }}\right), 4.80$ (m, 2H, $\left.\alpha \mathrm{H}-\mathrm{Cp}_{\text {subst }}\right)$; 6.83 (br-s, H, -OH). ${ }^{13} \mathrm{C} \mathrm{NMR}\left(\mathrm{CDCl}_{3}\right) \delta: 67.78-70.92[\mathrm{Fc}, \mathrm{C}(2-$ 10)]; 85.08 [Fc,C(1)]; 151.36(C=N).

(E)-Hydroxyiminoethylferrocene (3bE): Orange yellow flake. Yield $(\mathrm{E}+\mathrm{Z}): 84 \%$. m.p. $173-175^{\circ} \mathrm{C} . \mathrm{C}_{12} \mathrm{H}_{13} \mathrm{FeNO}$. Calcd. (\%) 56.03; H, 5.37; N, 9.33; found (\%) C, 55.91; H, 5.27; N, 9.42. IR (KBr, $\left.\nu_{\max }, \mathrm{cm}^{-1}\right): 3230(\mathrm{OH}) ; 1272(\delta \mathrm{OH})$; $1638(\mathrm{C}=\mathrm{N})$; $948(\mathrm{~N}-\mathrm{O}) .{ }^{1} \mathrm{H}$ NMR $\left(\mathrm{CDCl}_{3}\right) \delta: 1.90(\mathrm{~s}, 3 \mathrm{H}$, $\left.-\mathrm{CH}_{3}\right), 4.13$ (s, 5H, C $\left.\mathrm{p}_{\text {unsubst }}\right) ; 4.40\left(\mathrm{~m}, 2 \mathrm{H}, \beta \mathrm{H}-\mathrm{Cp}_{\text {subst }}\right), 4.60$ (m, $\left.2 \mathrm{H}, \alpha \mathrm{H}-\mathrm{Cp}_{\text {subst }}\right), 6.82$ (br-s, H, -OH). ${ }^{13} \mathrm{C} \mathrm{NMR}\left(\mathrm{CDCl}_{3}\right) \delta: 14.61$ $\left(\mathrm{CH}_{3}\right), 68.22-70.45$ [Fc, $\left.\mathrm{C}(2-10)\right] ; 85.41$ [Fc, C(1)]; 149.59 $(\mathrm{C}=\mathrm{N})$.

(Z)-Hydroxyiminoethylferrocene (3bZ): Orange yellow flake. m.p. 163-165 ${ }^{\circ} \mathrm{C} . \mathrm{C}_{12} \mathrm{H}_{13}$ FeNO. Calcd. (\%) 56.03; H, 5.37; N, 9.33; found (\%) C, 55.93; H, 5.29; N, 9.40. IR (KBr, $\left.v_{\max }, \mathrm{cm}^{-1}\right): 3240(\mathrm{OH}) ; 1278(\delta \mathrm{OH}) ; 1646(\mathrm{C}=\mathrm{N}) ; 952(\mathrm{~N}-\mathrm{O})$. ${ }^{1} \mathrm{H}$ NMR $\left(\mathrm{CDCl}_{3}\right) \delta: 1.89\left(\mathrm{~s}, 3 \mathrm{H},-\mathrm{CH}_{3}\right), 4.11\left(\mathrm{~s}, 5 \mathrm{H}, \mathrm{Cp}_{\text {unsubst }}\right)$; 4.43(m, 2H, $\left.\beta \mathrm{H}-\mathrm{Cp}_{\text {subst }}\right), 4.73$ (m, 2H, $\left.\alpha \mathrm{H}-\mathrm{Cp}_{\text {subst }}\right) .6 .90$ (br-s, $\mathrm{H},-\mathrm{OH}) .{ }^{13} \mathrm{C} \mathrm{NMR}\left(\mathrm{CDCl}_{3}\right) \delta: 15.08\left(\mathrm{CH}_{3}\right), 66.55-71.69$ [Fc,C(2-10)]; 84.33 [Fc,C(1)]; 148.65(C=N).

(E)-Hydroxyiminopropionylferrocene (3cE): Orangered flake. Yield $(\mathrm{E}+\mathrm{Z})$ : $78 \%$. m.p. $129-131^{\circ} \mathrm{C} . \mathrm{C}_{13} \mathrm{H}_{15} \mathrm{FeNO}$. Calcd. (\%) 60.73; H, 5.88; N, 5.45; found (\%) C, 61.01; H, 5.91; N, 5.50. IR (KBr, $\left.v_{\max }, \mathrm{cm}^{-1}\right): 3281(\mathrm{OH}) ; 1272(\delta \mathrm{OH})$; $1620(\mathrm{C}=\mathrm{N}) ; 942(\mathrm{~N}-\mathrm{O}) .{ }^{1} \mathrm{H}$ NMR $\left(\mathrm{CDCl}_{3}\right) \delta: 1.80(\mathrm{~m}, 2 \mathrm{H}$, $\left.-\mathrm{CH}_{2}\right), 1.25$ (t, 3H , $\left.-\mathrm{CH}_{3}\right), 4.19$ (s, 5H, Cp unsubst); 4.49 (m, 2H, $\left.\beta \mathrm{H}-\mathrm{Cp}_{\text {subst }}\right), 4.65\left(\mathrm{~m}, 2 \mathrm{H}, \alpha \mathrm{H}-\mathrm{Cp}_{\text {subst }}\right), 6.87(\mathrm{br}-\mathrm{s}, \mathrm{H},-\mathrm{OH}) .{ }^{13} \mathrm{C}$ NMR $\left(\mathrm{CDCl}_{3}\right) \delta: 7.79\left(\mathrm{CH}_{3}\right), 16.50\left(\mathrm{CH}_{2}\right), 67.74-69.77$ [Fc,C(2-10)]; 85.00 [Fc,C(1)]; 151.93(C=N).

(Z)-Hydroxyiminopropionylferrocene (3cZ): Orangered flake. m.p. $138-140{ }^{\circ} \mathrm{C} . \mathrm{C}_{13} \mathrm{H}_{15} \mathrm{FeNO}$. Calcd. (\%) 60.73; H, 5.88; N, 5.45; found (\%) C, 61.03; H, 5.94; N, 5.48. IR $\left(\mathrm{KBr}, \mathrm{v}_{\max }, \mathrm{cm}^{-1}\right): 3283(\mathrm{OH}) ; 1274(\delta \mathrm{OH}) ; 1624(\mathrm{C}=\mathrm{N}) ; 945$ $(\mathrm{N}-\mathrm{O}) .{ }^{1} \mathrm{H}$ NMR $\left(\mathrm{CDCl}_{3}\right) \delta: 1.81\left(\mathrm{~m}, 2 \mathrm{H},-\mathrm{CH}_{2}\right), 1.26(\mathrm{t}, 3 \mathrm{H}$, $\left.-\mathrm{CH}_{3}\right), 4.18$ (s, 5H, C $\left.\mathrm{p}_{\text {unsubst }}\right) ; 4.52\left(\mathrm{~m}, 2 \mathrm{H}, \beta \mathrm{H}-\mathrm{Cp}_{\text {subst }}\right)$, 4.75(m,2H, $\left.\alpha \mathrm{H}-\mathrm{Cp}_{\text {subst }}\right) .6 .84$ (br-s, H, -OH) ${ }^{13} \mathrm{C} \mathrm{NMR}\left(\mathrm{CDCl}_{3}\right)$

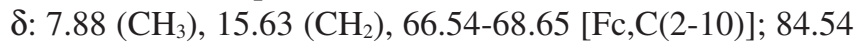
$[\mathrm{Fc}, \mathrm{C}(1)] ; 150.11(\mathrm{C}=\mathrm{N})$.

(E)-Hydroxyiminobutyrylferrocene (3dE): Orange-red powder. Yield $(\mathrm{E}+\mathrm{Z}): 74 \%$. m.p. $110-112{ }^{\circ} \mathrm{C} \cdot \mathrm{C}_{14} \mathrm{H}_{17} \mathrm{FeNO}$. Calcd. (\%) 62.01; H, 6.32; N, 5.17; found (\%) C, 61.91; H, 6.29; N, 5.19. IR (KBr, $\left.v_{\max }, \mathrm{cm}^{-1}\right): 3292(\mathrm{OH}) ; 1289(\delta 2 \mathrm{OH})$; $1640(\mathrm{C}=\mathrm{N}) ; 930(\mathrm{~N}-\mathrm{O}) .{ }^{1} \mathrm{H}$ NMR $\left(\mathrm{CDCl}_{3}\right) \delta: 1.92(\mathrm{t}, 2 \mathrm{H}$, $\left.-\mathrm{CH}_{2}\right), 1.52\left(\mathrm{~m}, 2 \mathrm{H},-\mathrm{CH}_{2}\right), 1.08\left(\mathrm{t}, 3 \mathrm{H},-\mathrm{CH}_{3}\right), 4.15(\mathrm{~s}, 5 \mathrm{H}$, $\left.C p_{\text {unsubst }}\right) ; 4.52$ (m, 2H, $\left.\beta \mathrm{H}-\mathrm{C} \mathrm{p}_{\text {subst }}\right), 4.63\left(\mathrm{~m}, 2 \mathrm{H}, \alpha \mathrm{H}-\mathrm{Cp}_{\text {subst }}\right)$, 6.97 (br-s, $\mathrm{H},-\mathrm{OH}) .{ }^{13} \mathrm{C} \mathrm{NMR}\left(\mathrm{CDCl}_{3}\right) \delta: 8.36\left(\mathrm{CH}_{3}\right), 11.30$ $\left(\mathrm{CH}_{2}\right), 15.95\left(\mathrm{CH}_{2}\right), 65.44-70.42[\mathrm{Fc}, \mathrm{C}(2-10)] ; 87.48$ [Fc, $\mathrm{C}(1)] ; 151.46(\mathrm{C}=\mathrm{N})$.

(Z)-Hydroxyiminobutyrylferrocene (3dZ): Orange-red powder, m.p. 119-121 ${ }^{\circ} \mathrm{C}, \mathrm{C}_{14} \mathrm{H}_{17}$ FeNO. Calcd. (\%) 62.01; H, 6.32; N, 5.17; found (\%) C, 61.93; H, 6.27; N, 5.18. IR ( $\mathrm{KBr}$, $\left.v_{\max }, \mathrm{cm}^{-1}\right): 3294(\mathrm{OH}) ; 1288(\delta 2 \mathrm{OH}) ; 1645(\mathrm{C}=\mathrm{N}) ; 935$ $(\mathrm{N}-\mathrm{O}) .{ }^{1} \mathrm{H}$ NMR $\left(\mathrm{CDCl}_{3}\right) \delta: 1.91\left(\mathrm{t}, 2 \mathrm{H},-\mathrm{CH}_{2}\right), 1.53(\mathrm{~m}, 2 \mathrm{H}$, $\left.-\mathrm{CH}_{2}\right), 1.09$ (t, 3H, $\left.-\mathrm{CH}_{3}\right), 4.14$ (s, 5H, $\left.\mathrm{Cp}_{\text {unsubst }}\right) ; 4.53$ (m, 2H, $\left.\beta \mathrm{H}-\mathrm{Cp}_{\text {subst }}\right), 4.80\left(\mathrm{~m}, 2 \mathrm{H}, \alpha \mathrm{H}-\mathrm{Cp}_{\text {subst }}\right) .6 .90$ (br-s, H, -OH). ${ }^{13} \mathrm{C}$ $\operatorname{NMR}\left(\mathrm{CDCl}_{3}\right) \delta: 8.00\left(\mathrm{CH}_{3}\right), 12.32\left(\mathrm{CH}_{2}\right), 15.54\left(\mathrm{CH}_{2}\right), 66.33-$ 71.20 [Fc, C(2-10)]; 86.85 [Fc, C(1)]; $152.63(\mathrm{C}=\mathrm{N})$. 
Evaluation of the antioxidative activity: All spectrophotometric measurements were performed with a UV/VIS LAMBOA-35 automatic spectrophotometer, under room temperature $\left(30^{\circ} \mathrm{C}\right)$. Standard solutions of the antioxidants were prepared in methanol and rapidly mixed (volumes from 0.015-0.2 mL) with a methanol solution of $\mathrm{DPPH}^{\bullet}$ (final volume $3 \mathrm{~mL}$ ). Initial concentrations of $\mathrm{DPPH}^{*}$ taken between $2.0 \times$ $10^{-5}$ and $2.2 \times 10^{-5} \mathrm{~mol}$ were used. The decrease in absorbance at $517 \mathrm{~nm}$ was recorded at different time intervals until the reaction reached a plateau (time at the steady state). Measurements per potential antioxidant were recorded with [antioxidant $] /\left[\mathrm{DPPH}^{\circ}\right]$ ratios in the range of $0.20-1.20$. In parallel, a blank solution of $\mathrm{DPPH}^{\bullet}$ was screened to estimate $\mathrm{DPPH}^{\bullet}$ decomposition during the time of measurement. The decrease in absorbance was then plotted against time.

\section{RESULTS AND DISCUSSION}

Preparation of acylferrocene (2a-d): Formylferrccene was prepared according to the modified method described ${ }^{28}$, acetylferrocene, propionylferrocene and butyrylferrocene were obtained by the Friedel-Crafts acylation ${ }^{29}$.

Preparation of hydroxyiminoalkylferrocene (3a-d): Hydroxyiminoalkylferrocene was prepared according to the modified method reported ${ }^{25,30}$. Aceylferrocene was condensed with hydroxylamine and produced $3 \mathbf{b}$ (Scheme-I). Considering the oxime being usually unstable and easily decomposed, excessive sodium hydroxide was added to the reaction solution, which easily completes the reaction with high yield, due to the rapid formation of ferrocenyl oxime in the alkaline condition and the ferrocenyl oxime, once formed, reacted with alkali immediately to produce stable ferrocenyl oxime sodium salt. The yield improved with increased amount of reactant hydroxylamine hydrochloride. The crude products was chromatographed on alumina with ethyl acetate as eluent and separated into two portions (the first eluted portion and the residual portion), respectively corresponding to the trans- and the $c i s$-isomer. The $c i s$-isomer differs from the trans-isomer in spectra and stability. In the NMR spectrum, an $\alpha$-proton on the $\mathrm{Cp}$ ring of the cis isomer should resonance at a considerably lower field and a higher Chemical shift $\left({ }^{1} \mathrm{H} \mathrm{NMR} / \delta, \mathbf{3 b}, \alpha \mathrm{H}-\right.$ $\mathrm{Cp}_{\text {subst }}$,trans: 4.60 ; cis: 4.73 ) than the trans isomer because of a steric compression effect of the $\mathrm{O}$ atom. In the IR spectrum of the cis isomer the line of $\mathrm{C}=\mathrm{N}$ stretching should appear at a higher frequency than that of the trans isomer (i.e.: IR, 3b; $v \mathrm{C}=\mathrm{N}$, trans: $1638 \mathrm{~cm}^{-1}$; cis: $\left.1648 \mathrm{~cm}^{-1}\right)$, since there is a considerable strain on the $\mathrm{C}=\mathrm{N}$ bond by hindrance between the $\alpha-\mathrm{H}$ of the $\mathrm{Cp}$ ring and the $\mathrm{OH}$ group. Yamakawa and Hisatome $^{29}$ reported that there is some general stereochemical correlation between the $\mathrm{C}=\mathrm{N}$ stretching band and $\mathrm{cis}$ and trans configurations in the oximes and the chemical shift of the protons near the hydroximino group would be competitively influenced by the deshielding effect of the $\mathrm{OH}$ group and by the diamagnetic anisotropic effect due to the lone-pair electrons of the $\mathrm{N}$ atom.

Formation of hydroxyiminoethylferrocene (3bE) was indicated by the IR spectra; the bands at $3230 \mathrm{~cm}^{-1}, 1272 \mathrm{~cm}^{-1}$, assigned to the $\mathrm{O}-\mathrm{H}$ group appeared. This result was confirmed from the broad band appearing in the ${ }^{1} \mathrm{H}$ NMR spectrum at

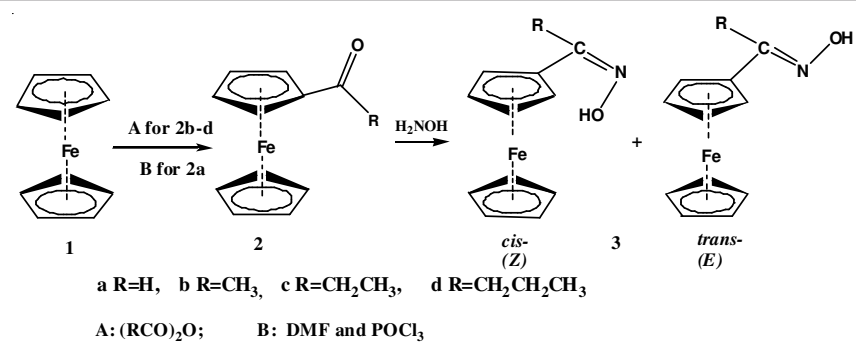

Scheme-I: Preparation of the 1-hydroxyiminoalkylferrocene

$6.82 \mathrm{ppm}$. The bands at 1638 and $948 \mathrm{~cm}^{-1}$ were assigned to $\mathrm{C}=\mathrm{N}$ and $\mathrm{N}-\mathrm{O}$, while the band at $1660 \mathrm{~cm}^{-1}$ due to $\mathrm{C}=\mathrm{O}$ group in aceylferrocene disappeared, indicating that the $\mathrm{C}=\mathrm{O}$ had been converted to $\mathrm{C}=\mathrm{N}$. Characterizations of the other compounds 3a, 3bZ, 3c and $\mathbf{3 d}$ from IR and ${ }^{1} \mathrm{H}$ NMR spectra were similar to $3 \mathbf{b E}$.

Antioxidant property: The stable free radical 2,2-diphenyl-1-picrylhydrazyl (DPPH ${ }^{\circ}$ ) is a useful reagent for investigating scavenger properties of phenols, catechols and aromatic amines, which usually contains $\mathrm{O}-\mathrm{H}$ and $\mathrm{N}-\mathrm{H}^{31-34}$. Based on this, the antioxidant activity of 1-hydroxyiminoethylferrocene was studied. Standard solutions of the acylferrocene oxime and BHT antioxidants were prepared in methanol and rapidly mixed with a methanolic solution of $\mathrm{DPPH}^{\bullet}$. The process of the reaction was followed by determining the decrease of the $\mathrm{DPPH}^{*}$ absorbance at $517 \mathrm{~nm}$. The decrease was plotted against time (Fig. 1). Plots of $1 /\left[\mathrm{DPPH}^{*}\right]$ versus time, obtained in the first 7 min during which the reaction follows second order kinetics, afforded straight lines (Fig. 2). The slopes of these lines were plotted against the ratio [antioxidant]/[ $\left.\mathrm{DPPH}^{*}\right]$ (Fig. 3); linear regression analysis $\left(\mathrm{r}^{2}>0.95\right)$ afforded the parameter $\mathrm{Z}$ (slope of the line in $\mathrm{L} \mathrm{mol}^{-1} \mathrm{~s}^{-1}$ ), which was examined as a quantification of radical scavenging activity. Since this parameter is derived from initial rates, it is markedly dependent on the reaction mechanism.

We measured the initial reaction rates (i.e., in the period during which second-order kinetics was maintained (Fig. 3). It is infered mechanism of reaction is by abstracting a hydrogen atom from a oxime donor to give diphenylpicrylhydrazine and a ferrocene hydroxyimino radical (Fig. 4). The reaction involves a colour change from violet to yellow which can easily be monitored by measuring the decrease in absorbance at $517 \mathrm{~nm}$. Since this parameter is derived from initial rates, it is markedly dependent on the reaction mechanism.

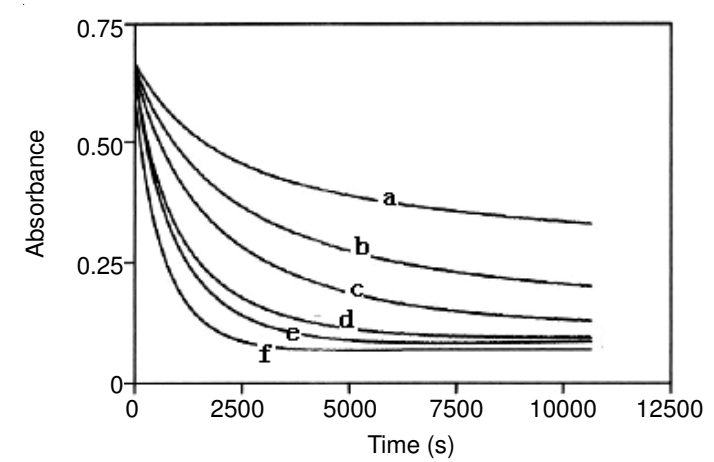

Fig. 1. Reaction of 3b with DPPH, monitored at 517 nm (a) 0.20 eqv., (b) 0.32 eqv., (c) 0.44 eqv., (b) 0.60 eqv., (e) 0.88 eqv., (f) 1.20 eqv. 


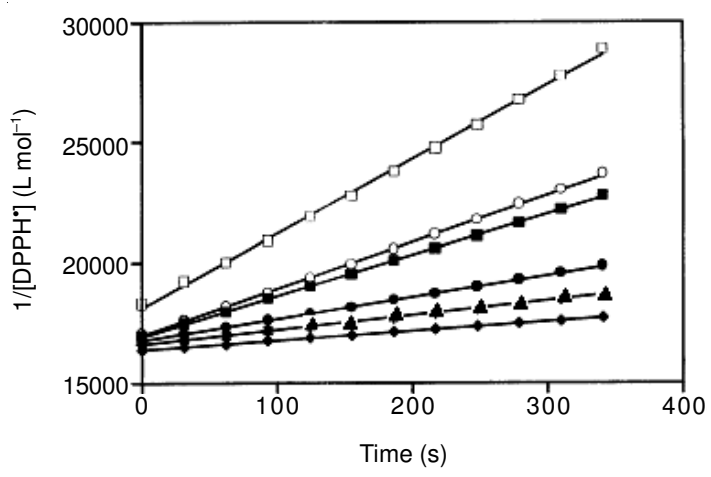

Fig. 2. Kinetics of the reaction of $\mathbf{3 b}$ with DPPH. ( $\square$ ) 0.20 eqv., $\mathbf{k}=3.98$;

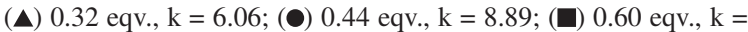
16.96 ; (O) 0.88 eqv., $\mathrm{k}=19.32$; () 1.20 eqv., $\mathrm{k}=30.88$ )

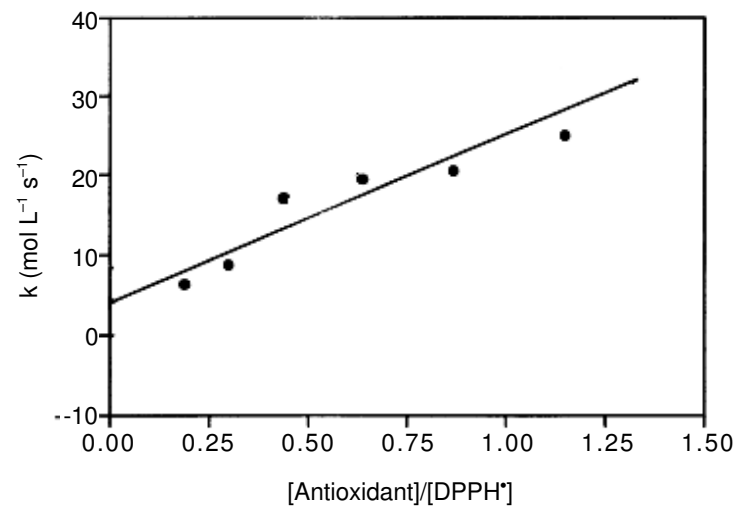

Fig. 3. Calculation of $Z$ for $3 b$ (regression parameters: slope $(Z)=22.96$, $\mathrm{r}^{2}=0.97, \mathrm{~s}=2.033, \mathrm{n}=6$ )

The better reactivity of acylferrocene oxime derivatives with $\mathrm{DPPH}^{\bullet}$ can be explained by a large stabilization of the ferrocene hydroxyimino radical due to a long conjugated chain, resulting in electron delocalization. According to $\log \mathrm{Z}$ value (Table-1), the free radical scavenging activities followed the order: $\mathbf{3 a}>\mathbf{3 b}>\mathbf{3} \mathbf{c}>\mathbf{3 d}>$ BHT, which indicated that the antioxidant activity was reduced as the bulkiness of the $\alpha$-substituent the hydroxyimino group (the alkyl carbon chain length) increased in structure-activity relationships. It reveals that there is a correlation between the stereochemistry and the antioxidant activity of the 1-hydroxyiminoalkylferrocenes. It was also found that acylferrocene oximes' precursors $\mathbf{2}$ and $\mathbf{1}$ have almost no antioxidant activity. In addition, the antioxidant activity of cis-isomers is slightly bigger than that of transisomers, this can be attributed to that in cis configurations, the $\mathrm{O}-\mathrm{H}$ bond is easily broken due to the steric effect between $\mathrm{O}$ atom of hydroxyimino group and $\alpha$-protons of the substituted $\mathrm{Cp}$ ring to form ferrocene hydroxyimino radicals. It is consistent
TABLE-1

KINETICS PARAMETERS FOR THE REACTION WITH DPPH ${ }^{\bullet}(\log Z)$

\begin{tabular}{cccc}
\hline Compounds & $\log \mathrm{Z}$ & Compounds & $\log \mathrm{Z}$ \\
\hline $\mathbf{3 a E}$ & 1.79 & $\mathbf{3 d Z}$ & 1.51 \\
$\mathbf{3 a Z}$ & 1.81 & $\mathbf{B H T}$ & 1.36 \\
$\mathbf{3 b E}$ & 1.63 & $\mathbf{2 a}$ & 0.05 \\
$\mathbf{b Z}$ & .65 & $\mathbf{2 b}$ & 0.06 \\
$\mathbf{c E}$ & .59 & $\mathbf{2 c}$ & 0.05 \\
$\mathbf{3 c Z}$ & 1.59 & $\mathbf{2 d}$ & 0.01 \\
$\mathbf{d E}$ & 1.48 & $\mathbf{1}$ & 0.02 \\
\hline
\end{tabular}

with the following: The cis oxime should be more acidic than the trans oxime, due to the stereochemical environment around the $\mathrm{H}$ atom of the hydroximino group. In fact, the trans form was eluted earlier than the cis form in column chromatography on alumina, due to the polarity of the cis molecular larger than that of the trans molecular.

\section{Conclusion}

A series of 1-hydroxyiminoalkylferrocenes with antioxidant activity from acylferrocenes were successfully prepared and characterized. The simplicity of the DPPH test offers an easy method to characterize radical scavengers acting mainly by hydroxyl hydrogen transfer. The kinetic parameter $\log \mathrm{Z}$ that derived from electron transfer from $\mathrm{DPPH}^{\bullet}$ was obtained. The result also indicates that 1-hydroxyiminoalkylferrocenes have better antioxidant properties than BHT, which are related to the stereochemistry of the $\alpha$-substituent hydroxyimino group. The free radical scavenging activities followed the order: $\mathbf{3} \mathbf{a}>\mathbf{3 b}>\mathbf{3} \mathbf{c}>\mathbf{3 d}>$ BHT. Antioxidant activity of cisisomers is slightly more than that of trans-isomers.

\section{ACKNOWLEDGEMENTS}

The authors express their thanks to the South-Central University for Nationalities for financial support during this investigation.

\section{REFERENCES}

1. J.O. Enlow, J. Hao, J.T. Grant, K. Eyink, W. Su and T.J. Bunning, Polymer, 49, 4042 (2008).

2. E.J. Kwon and T.G. Lee, Appl. Surf. Sci., 254, 4732 (2008).

3. X. Li, W. Liu, H. Zhang and B. Wu, J. Organometal. Chem., 693, 3295 (2008).

4. A.R. Sureshbabu, R. Raghunathan and B.K. Satiskumar, Tetrahedron Lett., 50, 2818 (2009).

5. M.F.R. Fouda, M.M.Abd-Elzaher and R.A. Abselsamaia, Appl. Organometal. Chem., 21, 613 (2007).

6. T. Hirao, J. Organometal. Chem., 694, 806 (2009).

7. M. Paticia, L. Virginie and S. Christian, Bioorg. Med. Chem. Lett., 16, 31 (2006).

8. C.N. Tharamani, H.F. Song, A.R.S. Ross, R. Hughes and H.-B. Kraatz, Inorg. Chim. Acta, 361, 393 (2008).

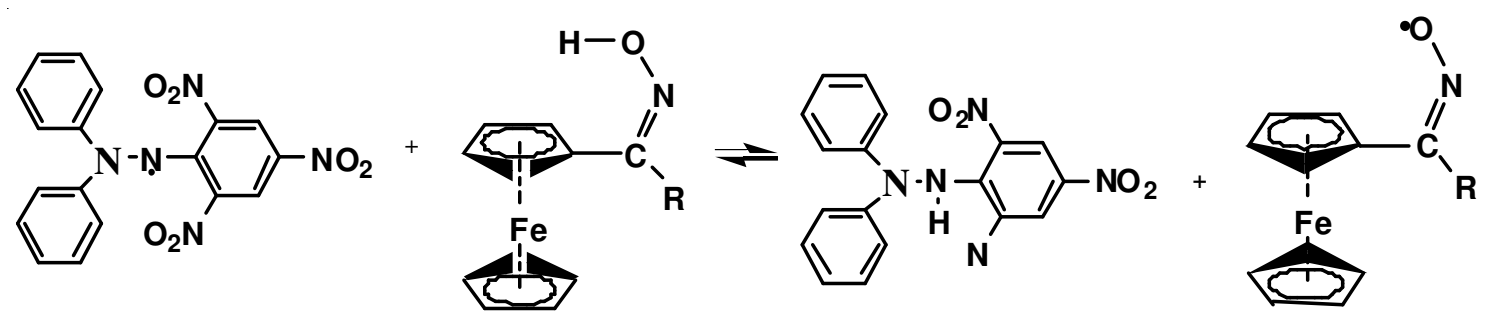

Fig. 4. First reaction step in the scavenging of the $\mathrm{DPPH}^{\bullet}$ radical by acylferrocene oxime 
9. C.J. McAdam, S.C. Moratti, B.H. Robinson and J. Simpson, J. Organometal. Chem., 693, 2715 (2008).

10. C.S. Allardyce, A. Dorcier, C. Scolaro and P. Dyson, Appl. Organometal. Chem., 19, 1 (2005).

11. Li K. Zhang and J. Zhang, Appl. Organometal. Chem., 22, 243 (2008).

12. Z. Feng, S. Yu and Y. Shang, Appl. Organometal. Chem., 22, 577 (2008).

13. P. Štepnicka, M. Krupa, M. Lamac and I. Císarová, J. Organometal. Chem., 694, 2987 (2009)

14. X. Shen, H. Miyashita, Qi Li, D. Zhu, M. Hashimoto and K. Sakata, Polyhedron, 27, 3105 (2008)

15. J.S. Casas, M.V. Castano, M.C. Cifuentes J.C., Garcia-Monteagudo, A. Sanchez, J. Sordo and U. Abram, J. Inorg. Biochem., 98, 1009 (2004).

16. L. Ma, L. Wang, Q. Tan, H. Yu, J. Huo, Z. Ma, H. Hu and Z. Chen, Electrochim. Acta, 54, 5413 (2009).

17. H. Zhou, Wi Yang and C. Sun, Talanta, 77, 366 (2008).

18. V. Lafitte, W. Wang, A.S. Yashina and N.S. Lawrence, Electrochem. Commun., 10, 1831 (2008).

19. X.Y. Wang, P. Dong, W. Yun, Y. Xu, P.G. He and Y.Z. Fang, Biosens. Bioelectron., 24, 3288 (2009).

20. J. Qiu, M. Deng, R. Liang and M. Xiong, Sens. Actuators B, 135, 181 (2008).

21. L. Chaicharoenwimolkul, A. Munmai, S. Chairam, U. Tewasekson, S. Sapudom, Y. Lakliang and E. Somsook, Tetrahedron Lett., 49, 7299 (2008).

22. J.C. Ndamanisha, Y. Hou, J. Bai and L. Guo, Electrochim. Acta, 54, 3935 (2009).
23. B. Long, S. Liang, D. Xin, Y. Yang and J. Xiang, Eur. J. Med. Chem., 44, 2572 (2009).

24. O. Fontaine, C. Lagrost, J. Ghilane, P. Martin, G. Trippé, C. Fave, J.C. Lacroix, P. Hapiot and H.N. Randriamahazaka, J. Electroanal. Chem., 632, 88 (2009).

25. J. Zhang, J. Chem. Res., 34, 68 (2010).

26. J. Ancerewicz, E. Migliavacca, P.A. Carrupt, B. Testa, F. Bree, R. Zini, J.P. Tillement, S. Labidalle, D. Guyot, A.M. Chauvet-Monges, A. Crevat and A.L. Ridant, Free Radic. Biol. Med., 25, 113 (1998).

27. P. Tosco, E. Marini, B. Rolando, L. Lazzarato, C. Cena, M. Bertinaria, R. Fruttero, M. Reist, P.A. Carrupt and A. Gasco, Chem. Med. Chem., 3, 1443 (2008).

28. M. Rosenblum, A.K. Baserjee, N. Danieli, R.W. Fish and V. Schlatte, J. Am. Chem. Soc., 85, 316 (1963).

29. C.R. Hauser and J.K. Lindsa, J. Org. Chem., 22, 482 (1957).

30. K. Yamakawa and M. Hisatome, Tetrahedron, 26, 4483 (1970).

31. C.A. Shaw, I.L. Megson and A.G. Rossi, Anti-Inflamm. Anti-Aller. Agents Med. Chem., 5, 27 (2006).

32. M. Constantin, C. Bromont, R. Fickat and R. Massingham, Biochem. Pharmacol., 40, 1615 (1990).

33. G.J. Papariello and M.A.M. Janish, Anal. Chem., 38, 21 (1966).

34. L. Valgimigli, J.T. Banks, K.U. Ingold and J. Lusztyk, J. Am. Chem. Soc., 117, 9966 (1995) 